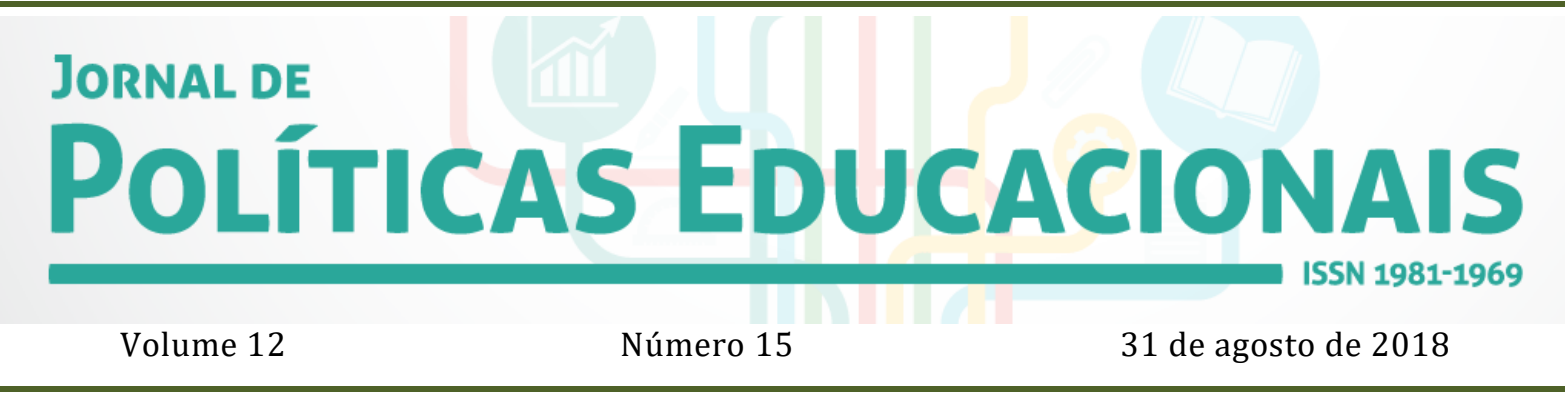

\title{
Apontamentos sobre o conceito de democracia em Joseph A. Schumpeter e Jürgen Habermas
}

\author{
Notes about democracy concept in Joseph A. Schumpeter and Jürgen \\ Habermas
}

\section{Apuntes sobre el concepto de democracia en Joseph A. Schumpeter y Jürgen Habermas}

Citação: SAKATA, K. L.; LIMA, M. F. Apontamentos sobre o conceito de democracia em Joseph A. Schumpeter e Jürgen Habermas. Jornal de Políticas Educacionais. V. 12, n. 15. Agosto de 2018.

http://10.5380/jpe.v12i0.59183

\section{Resumo}

Este texto objetiva refletir sobre o conceito de democracia em dois autores Joseph Alois Schumpeter (18831950) e Jürgen Habermas (1929-atual) e sua aproximação no âmbito escolar. Para tanto, indicou os aspectos históricos que fizeram emergir as democracias de massas ${ }^{3}$, refletiu o sentido de democracia nos dois teóricos supracitados e, por fim, analisou as convergências e as diferenças conceituais entre ambos. Os principais autores utilizados foram Habermas (1995; 2002), Pateman (1992) e Schumpeter (1984). Concluiu-se que, para os autores, a teoria democrática constitui-se como método governamental, e a participação popular das massas tem sentidos opostos, para Schumpeter ela é desnecessária e, para Habermas, essencial.

Palavras-chave: Teoria democrática, Participação, Gestão escolar.

\section{Abstract}

This text aims to reflect about the concept of democracy in two authors, Joseph Schumpeter (1883-1950) and Jürgen Habermas (1929-current) and their approximation in the school system. To accomplish such

\footnotetext{
${ }^{1}$ Mestranda em Educação pela Universidade Estadual do Centro-Oeste - UNICENTRO e integrante do Grupo de Pesquisa Estado, Política e Gestão em Educação (UNICENTRO-IRATI). Professora do Colégio Pontagrossense-PR. E-mail: kelly.l.sakata@hotmail.com

2 Doutora em Educação (UFPR). Professora da Universidade Estadual do Centro-Oeste: Câmpus Irati (PR) e do Programa de Pós-Graduação em Educação. E-mail: mfernandeslima@yahoo.com.br ${ }^{3}$ A Democracia de massas é a ideia moderna do conceito de democracia pensada por Marcos Nobre (2004).
} 
task, it indicated the historical aspects which made emerge the mass democracies, reflected the meaning of democracy in both afore mentioned theorists, and lastly, it analyzed the convergences and the conceptual differences between both. The main authors utilized were Habermas (1995; 2002), Pateman (1992) and Schumpeter (1984). It was concluded that to the authors, the democratic theory is constituted as a government method, and the popular participation of the masses has opposite meanings, to Schumpeter it is unnecessary and to Habermas it is essential.

Keywords: Democratic theory, Participation, School management.

\section{Resumén}

Este texto objetiva reflexionar sobre el concepto de democracia en dos autores, Joseph Schumpeter (18831950) y Jürgen Habermas (1929-actual) y su aproximación en el ámbito escolar. Para ello, indicó los aspectos históricos que hicieron emerger las democracias de masas, reflejó el sentido de democracia en los dos teóricos citados y, por fin, analizó las convergencias y las diferencias conceptuales entre ambos. Los principales autores utilizados fueron Habermas $(1995,2002)$, Pateman (1992) y Schumpeter (1984). Se concluyó que, para los autores, la teoría democrática se constituye como método gubernamental, y la participación popular de las masas tiene sentidos opuestos, para Schumpeter es innecesaria y, para Habermas, esencial.

Palabras clave: Teoría democrática, Participación, Gestión escolar.

\section{Introdução}

O conceito de democracia é complexo, transcendental e está presente na sociedade desde tempos remotos. Etimologicamente, o termo democracia vem do grego demokratía, governo do povo. Governo em que o povo exerce a soberania, direta ou indiretamente 4 . Sua definição, como forma de Estado e sob um viés histórico, depende do tipo de sociedade em que está inserido e, principalmente, de quem é considerado apto a participar das decisões.

Sob este prisma encontra-se a importância de estudos sobre o conceito de democracia, no fomento da problematização e reflexão dos seus aspectos e, principalmente, na emergência de trazer consciência sobre os pontos que perpassam as questões políticas, as quais influenciam diretamente o nosso cotidiano, especialmente, o cotidiano escolar.

O presente trabalho objetiva refletir o conceito de democracia em dois autores, Joseph Alois Schumpeter e Jürgen Habermas. Eles foram estudados no âmbito do Programa de Pós-Graduação em Educação da Universidade Estadual do Centro-Oeste UNICENTRO, em que se discutiu a importância de seus estudos. Trata-se de reflexões iniciais, pois compreendemos que os dois autores são clássicos e o aprofundamento teórico ultrapassaria as dimensões deste artigo. No entanto, são entendimentos iniciais que poderão servir de aporte para um aprofundamento futuro dos interessados em

\footnotetext{
${ }^{4}$ Dicionário priberam on-line. Disponível em: $<$ https://www.priberam.pt/dlpo/democracia $>$. Acesso em: 05 jun. 2017.
} 
SAKATA, K. L.; LIMA, M. F. Apontamentos sobre o conceito de democracia em Joseph A. Schumpeter e Jürgen Habermas.

discutir democracia e seus fundamentos no fomento da gestão democrática no âmbito escolar.

Este trabalho inicia-se com indicações a respeito dos aspectos históricos que influenciaram as mudanças no conceito de democracia, principalmente a partir do século XIX. Após, reflete sobre os pontos do conceito de democracia em Schumpeter e Habermas, e conclui sobre as convergências e diferenças entre os dois autores.

Para nós, o conceito de democracia, nos dois autores, não é compatível em uma sociedade capitalista. Acreditamos que democracia é um conceito que está atrelado a uma emancipação humana ${ }^{5}$ e, neste tipo de sociedade, temos apenas uma emancipação formal. Deste modo, a democracia que defendemos está neste limite e concorda com Habermas, na defesa de maior participação popular e no fomento de trazer consciência à população das massas quanto à importância desta participação para conseguir transformar, na medida do possível, a sociedade atual. Assim, no âmbito escolar, vários atores são chamados a participar: professores, pedagogos, pais, alunos, funcionários, etc., e contribuir para uma transformação que permita a efetivação da gestão democrática.

\section{Aspectos históricos: a emergência das democracias de massas}

Atualmente, democracia é um conceito que ultrapassa os limites governamentais, e está diluído no seio social, obtendo aceitação quase unânime da sociedade. Segundo Nobre (2004), a ideia moderna de democracia é recente e tem pouco mais de um século, em que alguns processos históricos influenciaram seu sentido, como o welfare state, a emergência de regimes totalitários e a influência da globalização. 0 welfare state é entendido como fornecimento de "[...] serviços sociais, cobrindo as mais variadas formas de risco da vida individual e coletiva, tornou-se um direito assegurado pelo Estado a camadas bastante expressivas da população dos países capitalistas desenvolvidos" (ARRETCHE, 1995, p. 1). Ele se expandiu e popularizou-se no período de pós-guerra, entre 1945 a 1973.

A emergência deste regime ocorreu por uma das maiores crises do capitalismo, decorrente de um acirrado aceleramento industrial, marcado pelo consumismo das classes dominantes e dos regimes totalitários em alguns países da Europa. Neste sentido,

\footnotetext{
${ }^{5}$ Para Tonet, a emancipação humana está para além do conceito de cidadania, e só seria conquistada em um trabalho associado e sem alienações. (TONET, I. Socialismo e democracia, 2007). Disponível em: <http://ivotonet.xpg.uol.com.br/arquivos/socialismo_e_democracia.pdf >. Acesso em: 10 jun. 2017.
} 
o ideal clássico de democracia, “[...] compreendida fundamentalmente na acepção rousseauniana, que é centrada nos princípios da soberania popular, da deliberação direta e da construção da 'vontade geral', e pelo utilitarismo inglês do século XIX" (RÊGO, 1994, p. 1, grifo do autor), foi questionada por alguns teóricos.

A questão que apareceu não foi direcionada na recusa da democracia, mas no grau de participação popular das massas. Elas começaram a ser entendidas dentro da lógica dos regimes totalitários.

O Fantasma do totalitarismo também ajuda a explicar as condições necessárias à estabilidade num Estado democrático; outro fator neste sentido era a instabilidade de tantos estados num mundo pós-guerra, em especial as ex-colônias, que apenas em poucos casos mantiveram um sistema político democrático nos moldes ocidentais (PATEMAN, 1992, p. 11).

O welfare state emerge como ponto de contenção da crise de regimes totalitários e de um liberalismo econômico desenfreado, sendo o seu ápice a crise em 1929, marcada pela quebra da bolsa de valores em Nova York. Neste sentido, o welfare state não foi estabelecido de forma igualitária em todos os lugares do mundo e não ocorreu de forma pacífica,

[...] resultou de uma ampla negociação entre movimentos sociais, sindicatos, entidades patronais, partidos políticos e burocracia estatal. 0 resultado desta ampla negociação política foi à concretização de uma variada gama de direitos sociais, cuja implementação passou a ser obrigação do Estado (NOBRE, 2004, p. 26).

Essas séries de acontecimentos históricos, além de trazerem uma mudança de visão sobre o caráter da participação das massas, indicam pontos positivos e negativos dentro do seio social. Os pontos negativos concentram-se em uma dependência da população à burocracia estatal, observada pela apatia política e participativa, em que a participação é entendida, na maioria das vezes, como o voto nas eleições. Este fato é entendido por Pateman (1992 p. 11) como consequência do totalitarismo e decorrência da expansão da sociologia política. Alguns teóricos democráticos da atualidade expandem (erroneamente) a idéia desta apatia participativa atrelada a uma não qualidade das massas populares à participação política. 0 ponto positivo foi a concretização, em alguns países, de direitos sociais que, para uma grande parcela da população de baixa renda, foi bastante significativo.

Arretche (1995) problematiza, em seu estudo, que o welfare state foi resultado de uma ampliação progressiva de direitos. Relata que Cidadania e Classe Social são grande 
SAKATA, K. L.; LIMA, M. F. Apontamentos sobre o conceito de democracia em Joseph A. Schumpeter e Jürgen Habermas.

fonte intelectual da explicação, que se baseia na ideia de ampliação progressiva da noção de cidadania. Ela compreende três tipos de direitos: os direitos civis, os políticos e os sociais, séculos XVII, XIX e XX respectivamente. A evolução de cada dimensão dos direitos é explicada pela universalização, isto é, a ampliação progressiva das camadas sociais que a eles tinham acesso. Significa que o welfare state resulta deste processo histórico, que fomenta segurança e reduz a sensação de incertezas, fazendo emergir uma renovação dos laços sociais.

Este aparato jurídico, visualizado por meio dos direitos, está atrelado ao conceito moderno de cidadania e, segundo Nobre (2004, p. 27),

[...] no desenvolvimento histórico concreto do Welfare State, o registro jurídico-burocrático foi hipertrofiado e prevaleceu amplamente sobre o registro do fomento da autonomia pública e privada dos cidadãos, às expensas, portanto, da consolidação e do aprofundamento de uma cultura política democrática.

O welfare state não intencionava fomentar a participação das massas, mas conter a crise emergente através de um discurso pró-democrático que, na verdade, foi engessado pela burocracia, e a população só participaria via partidos políticos, através do voto. Para o autor, entre outros críticos $^{6}$, este movimento fomentava retirar a reflexão política das massas, tornando-as trabalhadores dependentes.

Compreendemos, ainda de acordo com Nobre (2004, p. 23), uma incompatibilidade entre o conceito de democracia, entendida como "um governo do povo", com o modo vigente de uma sociedade capitalista. Vimos que a emergência do welfare state mudou o sentido de democracia, antes atrelado às concepções clássicas, neste período, um conceito de democracia atrelado à cidadania.

Segundo Barros, Barbosa e Alves (2014, p. 88), o crescimento econômico do welfare state,

[...] junto com a obtenção de elevadas taxas de lucratividade perdurou durante três décadas, porém, teve como elemento limitante a própria lógica que rege a acumulação capitalista e suas contradições. [...] Contudo, a longa onda de crescimento começa a sinalizar que estaria perdendo força já a partir do final da década de 1960 e no decênio seguinte a economia capitalista mundial entra num processo de brusca desaceleração, o que acabou por implicar na redução das taxas de lucratividade.

\footnotetext{
${ }^{6}$ Arretche (1995) destaca alguns autores que explicam o Welfare State por meio de fatores relacionados à luta de classes, a distintas estruturas de poder político, estruturas estatais ou institucionais. Dentre eles estão: T. H. Marshall, Ian Gough, Esping-Andersen, ThedaSkocpol, Ann Shola Orloff, Margareth Wei e Hugh Heclo, que têm como destaque o trabalho Modern Social Politics in Britain and Sweden.
} 
O declínio do welfare state, motivado principalmente pela crise fiscal dos Estados, trouxe desaceleração e colocou em xeque a eficácia ocorrida, até então, entre a democracia das massas e o capitalismo. Para além, está a falta de sustentação da cidadania sob o welfare state que, para Nobre (2004, p. 28), está ligada à atuação “[...] dos novos movimentos sociais, a derrocada do socialismo real, as novas formas de circulação e de acumulação do capital, mas também o rompimento da identidade entre cidadão e trabalhador produzida pelo welfare state".

Atualmente, devido à globalização ${ }^{7}$ e sob a lógica neoliberal ${ }^{8}$, ao mesmo tempo em que cada Estado trabalha para se fortificar frente aos outros países, devido à concorrência e competitividade, ele se alia a outros, formando blocos econômicos. Neste prisma, o sentido de democracia das massas perpassa as negociações entre a população e o Estado e entre os Estados, tornando-se mais complexo. Desta maneira, emergem formas diversas de participação, impulsionadas por novas organizações populares, entre elas estão as denominadas minorias.

Para Ugarte (2004, p. 93), os elementos de participação e cidadania “[...] não são pelo menos não por si mesmas- as que outorgam significado ao conceito de democracia. Afirmar que 'democracia é a forma de governo na qual os cidadãos participam' é apenas parte da verdade". Deste fato surgem teorias diversas sobre o conceito de democracia, com diferenciações que abrangem os aspectos da participação, quanto a quem, como e em que situação participar. 0 autor destaca que as teorias sobre democracia estão além de uma mera questão semântica, possuem valor axiológico, mesmo as que se propõe a descrever a verdade, as chamadas realistas, possuem cunho normativo.

Após esta pequena explanação sobre alguns determinantes históricos, os quais influenciaram o sentido de democracia e fizeram emergir a democracia das massas, passamos a uma reflexão sobre o sentido de democracia em Joseph Alois Schumpeter e Jürgen Habermas.

\footnotetext{
${ }^{7}$ Segundo Libâneo, Oliveira e Toshi (2012, p. 85 e 87), a globalização é “[...] visível, por exemplo, no processo de entrelaçamento da economia mundial, por meio de mercados comuns ou blocos econômicos, como a União Européia (UE), o acordo de Livre-Comércio da América do Norte (Nafta), o Mercado Comum do Sul (MERCOSUL), entre outros [...] ocorre em grande parte, graças à atuação das corporações mundiais ou transnacionais, como Mitsubishi, Coca-Cola, Unilever, Nestlé, PEPSICO, Texaco, BP, Honda, France Telecom, General Motors, Ford, Volkswagen, Renault, Shell e outras que atuam praticamente em todos os países".

8 "A partir de 1980, através do tatcherismo e do regganismo, assistiu-se ao surgimento das chamadas 'políticas neoliberais' (com a redução do papel do Estado e a criação de mercados, ou quase mercados, nos setores tradicionalmente públicos - saúde, educação, transportes etc.)" (BARROSO, 2005, p. 741).
} 


\section{Conceito de Democracia: Joseph Alois Schumpeter}

A escolha dos autores para estudo ocorreu devido às suas redefinições, um tanto radicais, do conceito de democracia. As duas teorias aprofundam-se em uma questão especial, a participação das massas populares, e se encontram no grupo das democracias modernas. Como veremos, em sentidos opostos, a participação popular é defendida por Habermas e refutada por Schumpeter, que despreza as questões populares, na medida em que acredita na democracia apenas atrelada ao parlamento e aos trâmites de mercado, encarando-a apenas como método.

Para Rêgo (1994, p. 15), a teoria democrática schumpeteriana “[...] inscreveu-se talvez como a primeira e mais importante contribuição no conjunto de teorias democráticas chamadas pós-clássicas. Inaugurou, assim, um conjunto de reflexões instigante e fecundo e, certamente por isso, pleno de paradoxos".

Schumpeter viveu entre1883 a 1950, e sua teoria, segundo Pateman (1992), é uma revisão das teorias clássicas, pois, naquele período específico de emergência dos regimes totalitários, havia o argumento de que as teorias clássicas eram consideradas normativas e carregadas de valor. Estas teorias não seriam suficientes para explicar o novo momento, ao passo que uma teoria moderna seria científica e empírica. Portanto, o autor atribuiu, à democracia, uma visão pragmática e o seu valor residirá na sua funcionalidade e eficácia instrumental.

A democracia em Schumpeter será despida de qualquer valor ético e moral, sua proposta de teoria é centrada na competição pela liderança política, em seu livro Capitalismo, socialismo e Democracia (1984), além de discorrer sobre o capitalismo e o socialismo em uma visão sociológica moderna e com ênfase na economia política, o autor tece críticas à fórmula clássica da teoria democrática, propondo uma nova teoria. Em sua crítica, concentra-se no papel do bem comum e da vontade do povo. Sobre o bem comum, Schumpeter (1984, p. 314-316, grifos do autor) argumenta três proposições:

Em primeiro lugar, não existe algo que seja um bem comum unicamente determinado, sobre o qual todas as pessoas concorrem ou sejam levadas a concordar através de argumentos racionais. [...] Em segundo lugar, mesmo que um bem comum suficientemente definido - tal como, por exemplo, o máximo utilitarista de satisfação econômica - se mostrasse aceitável para todos, isso não implicaria respostas igualmente definidas para as questões isoladas. [...] Mas, em terceiro lugar, dissipa-se no ar, em conseqüência das duas proposições anteriores, o conceito particular de vontade do povo (ou volonté générale), que os utilitaristas fizeram seu. 
Pois tal conceito pressupõe a existência de um bem comum unicamente determinado e capaz de ser percebido por todos.

Schumpeter considera que não existe um bem comum genuíno, na medida em que não existe uma consciência coletiva e um valor racional sobre este bem. 0 autor indica esta questão como um conceito do romantismo, desprovido de critérios científicos. Neste sentido, não existindo um bem comum, não existirá uma vontade do povo. Nas palavras do autor (1984, p, 317), “[...] ficamos ainda com a necessidade prática de atribuir à vontade do indivíduo uma independência e uma qualidade racional que são de todo irrealistas".

0 autor problematiza a participação das massas indicando uma falta de capacidade de observação e interpretação corretas em relação às informações que perpassam as questões políticas. Ugarte (2004, p. 97), ao interpretar Schumpeter, aponta que, em sua visão, “[...] devemos observar o processo democrático com realismo, aceitando que os indivíduos são portadores de interesses egoístas que, em sua maioria, são incapazes de participar na tomada das decisões importantes da agenda política".

Ao tentar compreender e estabelecer uma aproximação ao raciocínio de Schumpeter indicamos, como necessário, fazer um paralelo sobre o plano histórico em que está imerso o autor. Deste modo,

A realidade, o poder avassalador do mercado e as possibilidades de fabricação dos elementos volitivos constituem o solo sobre o qual trabalha pragmaticamente Schumpeter. Este nos diz da ilusão do utilitarismo benthamista, por não poder considerar as inúmeras "possibilidades de corrupção em massa do capitalismo contemporâneo.". Nega, pois o postulado benthamiano de que o povo é o melhor juiz de seus próprios interesses individuais e que estes deveriam coincidir com os interesses da população como um todo (RÊGO, 1994, p. 2, grifos do autor).

A realidade empírica, na qual Schumpeter se baseia, mostra ser contrária em relação à perspectiva da teoria clássica democrática, explicando seu modo de pensar e sendo considerado, por autores posteriores a ele, como realista.

No livro supracitado, Schumpeter (1984), após argumentar sobre o bem comum e a vontade do povo, tece críticas à natureza humana na política. Destacamos dois trechos sobre suas considerações em relação a esta natureza, tendo por base os estudos de Gustave Le Bon ${ }^{9}$, em quem Schumpeter se ampara:

\footnotetext{
${ }^{9} \mathrm{O}$ autor foi o primeiro expoente efetivo da psicologia das massas, propõe e apresenta como imperiosa uma psicologia das multidões, em que discorre que as multidões devem ser guiadas por uma pequena aristocracia. Disponível em: <http://www.scielo.br/pdf/ptp/v16n2/4377.pdf>. Acesso em: 10 jun. 2017.
} 
Ao mostrar, embora exagerando, as realidades do comportamento humano quando sob a influência da aglomeração - em particular, o desaparecimento súbito, em estado de excitação, de restrições morais e de modos civilizados de pensar e sentir, a súbita erupção de impulsos primitivos, de infantilismos e de propensões criminosas -, ele nos faz ver fatos repulsivos que todos conheciam, mas que ninguém queria ver, e, portanto dá um sério golpe no quadro da natureza humana subjacente à doutrina clássica da democracia e ao folclore democrático acerca das revoluções (SCHUMPETER, 1984, p. 321).

Schumpeter, amparado pelos estudos da psicologia da época e por razões empíricas, entende que as massas populares, além de não possuírem uma vontade genuína, autônoma e coletiva, possuem baixo nível de inteligência, característica que se estende a boa parte das classes sociais. A seu ver, apenas uma pequena parcela da sociedade possui um grau elevado para as questões que dependem da razão, especialmente no que se refere às questões políticas. Para o autor, os únicos que podem participar das decisões políticas são os membros das elites, por meio dos partidos.

Após seus argumentos quanto à ineficiência e a falta de realismo da teoria democrática clássica, Schumpeter indica sua proposta de teoria democrática. Esta operação significou uma ruptura decisiva com a relação clássica entre soberania e representação. Neste sentido, seu conceito de democracia "[...] reduz-se ao conjunto de procedimentos para decidir, sem importar-se se os que decidem são dez, cem ou mil cidadãos" (UGARTE, 2004, p. 97).

Para além das questões de participação popular das massas que, para Schumpeter, não tinha relevância, pois ele voltava seu interesse ao método, estão as questões das finalidades a que se propõem as políticas. Portanto emerge, desta proposição, a sua relação com os partidos políticos. Deste modo, Nobre (2004, p. 31) indica que democracia, para Schumpeter,

[...] é a luta entre líderes políticos rivais, pertencentes a partidos e disputando o direito de governar. Trata-se, portanto, de um modelo em que democracia passa a ser um arranjo institucional capaz de produzir decisões necessárias à reprodução social e econômica nas condições de uma sociedade pós-tradicional, em que não há um mesmo conjunto de valores últimos partilhados por todos os membros do corpo político.

Schumpeter, ao discorrer sobre sua teoria democrática indica, como elemento primordial, a competição pela liderança política. Esta luta será travada entre os partidos em que os seus líderes serão escolhidos pelos cidadãos, através do voto. Ao serem escolhidos, eles poderão trabalhar autonomamente, pois a escolha do líder supõe sua 
autoridade e qualidade nas decisões, não implicando necessariamente uma consulta à população. Em suas palavras, “[...] o método democrático é aquele acordo institucional para se chegar a decisões políticas em que os indivíduos adquirem o poder de decisão através de uma luta competitiva pelos votos da população" (SCHUMPETER, 1984, p. 336).

Esta luta competitiva pelos votos significa que a vontade do povo já discorrida no presente trabalho, além de não ser genuína, é manufaturada. Schumpeter (1984) discorre sobre a questão da propaganda, a luta travada para a conquista de votos, que ocorre por meio do convencimento das massas. 0 autor indica que a irracionalidade da população perpassa, inclusive, a não consciência desta luta e deste convencimento definido pela propaganda.

Schumpeter fazia uma comparação entre a competição política por votos e o sistema de mercado econômico: “[...] à maneira dos consumidores, os eleitores escolhem entre as políticas (produtos) oferecidas por empresários políticos rivais, e os partidos regulam a competição do mesmo modo que as associações de comércio na esfera econômica" (PATEMAN, 1992, p. 13).

Entendemos, pelos estudos, que a teoria schumpeteriana e suas indicações realistas sobre o método democrático influenciaram muitos autores que vieram posteriormente. Essas indicações que se propuseram realistas tornaram-se normativas, e um marco entre a teoria clássica de democracia e as democracias modernas de massas. Passamos, agora, à reflexão sobre a teoria democrática das massas em Habermas.

\section{Conceito de democracia: Jürgen Habermas}

Habermas nasceu em 1929, filósofo e sociólogo alemão, é considerado um dos mais importantes intelectuais contemporâneos ${ }^{10}$. Sua teoria democrática é conhecida como Democracia Deliberativa, em que indica um modelo de ação comunicativa. Nesta teoria, a sociedade cria regras por meio de um consenso e de forma não coercitiva. Neste sentido, existe a proposta de participação das massas exercida por deliberação e com ênfase no processo discursivo. Esta teoria é denominada por Habermas como procedimental, e está associada a uma ética discursiva.

Entendemos que o debate atual sobre o conceito de democracia está centrado sobre o sentido de participação e deliberação. Deste modo, a escolha do autor supracitado

\footnotetext{
${ }^{10}$ Informações sobre a vida e obra de Habermas disponíveis em:

<http://intervox.nce.ufrj.br/ ballin/habermas.doc >. Acesso em: 08 jun. 2017.
} 
procede porque "[...] a sua proposta de compreender procedimentalmente a democracia tem sido um ponto de referência central nesses debates" (NOBRE, 2004, p. 35). Para os autores deliberativistas, os cidadãos “[...] estão inspirados por um espírito cooperativo, atuam com razoabilidade - que não se reduz a uma mera racionalidade interessada - e se respeitam mutuamente" (UGARTE, 2004, p. 98).

Habermas (2002) discorre sobre a diferença entre a concepção republicana e liberal de democracia, indicando que a principal diferença entre ambas é o papel no processo democrático. Para o autor, na concepção liberal, o sentido de processo democrático consiste na programação do Estado no "[...] interesse da sociedade, entendendo-se o Estado como o aparato de administração pública e a sociedade como o sistema, estruturado em termos de uma economia de mercado, de relações entre pessoas privadas e do seu trabalho social" (HABERMAS, 2002, p. 277-287). Na concepção republicana, a mediação entre o Estado e a sociedade não é a única função da política, ela "[...] é um elemento constitutivo do processo de formação da sociedade como um todo. A política é entendida como uma forma de reflexão de um complexo de vida ético" (HABERMAS, 2002, p. 277-287).

Neste sentido, Nobre (2004, p. 35-36, grifos do autor) reflete sobre a diferença entre as duas concepções, e indica que elas “[...] podem ser referidas a uma oposição entre 'a liberdade dos antigos' e a 'liberdade dos modernos', que virá a se mostrar, por sua vez, na concorrência entre 'direitos humanos' e 'soberania popular'”.

A questão do embate nessas duas concepções se encontra no grau e no processo de participação das massas populares. Para a concepção republicana, há que existir a soberania de uma coletividade política, a nosso, ver pelo viés da teoria democrática clássica. Na concepção liberal, por meio dos direitos humanos, é lançado um limite dessa participação das massas. Neste sentido, é o caso da teoria da democracia de Schumpeter.

Habermas (2002), após expor essas duas concepções de teorias, indica a sua teoria democrática, como forma de reconciliar essas questões, as quais foram expostas, de participação das massas populares. 0 autor expõe a dificuldade em desenvolver uma teoria democrática considerada justa, devido à complexidade da sociedade atual. Nesta sociedade, para além das questões políticas propriamente ditas, emergem questões de demandas decorrentes da pluralidade cultural, devido à globalização, e do movimento das minorias. Para o autor, se nós, como "[...] participantes de discursos políticos, não pudéssemos convencer outras pessoas, nem aprender com elas, a política deliberativa 
perderia seu sentido - e o Estado democrático de direito, o fundamento de sua legitimação" (HABERMAS, 2002, p. 326).

Entendemos que sua proposta se baseia no processo procedimental, em que os cidadãos participam expondo suas opiniões e aprendendo no processo, sem perder de vista um caráter de tentativa de acertos em suas decisões. Assim, Habermas (1995) indica sua teoria do discurso, baseando-se nas reflexões das duas concepções elencadas, na tentativa de superá-las. A teoria do discurso,

[...] diferentemente, conta com a intersubjetividade de ordem superior de processos de entendimento que se realizam na forma institucionalizada das deliberações, nas instituições parlamentares ou na rede de comunicação dos espaços públicos políticos. Essas comunicações desprovidas de sujeito, ou que não cabe atribuir a nenhum sujeito global, constituem âmbitos nos quais pode dar-se uma formação mais ou menos racional da opinião e da vontade acerca de temas relevantes para a sociedade como um todo e acerca das matérias que precisam de regulação. A geração informal da opinião desemboca em decisões eleitorais institucionalizadas e em decisões legislativas por meio das quais o poder gerado comunicativamente se transforma em poder passível de ser empregado em termos administrativos. [...] As implicações normativas saltam à vista: a força da integração social que tem a solidariedade social, não obstante não mais poder ser extraída somente das fontes da ação comunicativa, deve poder desenvolver-se com base em amplamente diversificados espaços públicos autônomos e em procedimentos de formação democrática da opinião e da vontade políticas, institucionalizadas em termos de Estado de Direito; e, com base no meio do Direito, deve ser capaz de afirmar-se também contra os outros dois poderes -o dinheiro e o poder administrativo (HABERMAS, 1995, p. 48).

O autor explica que a teoria do discurso consiste em uma organização da opinião, que ocorre a partir de traduções como, por exemplo, da linguagem usada nos âmbitos jurídicos para o senso comum e vice e versa, para que, na discussão, todos os envolvidos possam se entender e emitir opinião. Para além, indica uma forma institucionalizada de aconselhamentos. Nas palavras de Nobre (2004, p. 37), para a deliberação e a participação estar vigente na sociedade atual, será “[...] necessário aceitar um jogo entre, de um lado, espaços públicos autônomos e as novas formas de institucionalidade que projetam, e, de outro, macroestruturas definidoras do regime democrático [...]".

Segundo Ugarte (2004), alguns autores tecem críticas à perspectiva teórica deliberalista, principalmente quanto ao seu cunho idealista, de acreditar que os cidadãos possam desenvolver respeito sobre as opiniões contrárias as suas, e sobre o consenso ser um termo constituído em um ideal pré-moderno. Neste sentido, a debilidade da teoria deliberativa está em “[...] apostar tudo em uma “opinião pública” livre, culta, responsável, 
informada e disposta a participar, capaz de exercer uma função propositiva inteligente e de controle do poder político que, além de inexistente parece utópica" (UGARTE, 2004, p. 99).

Ao responder algumas críticas que são enunciadas à sua teoria, Habermas (2002, p. 327, grifos do autor) indica,

Entre os procedimentos decisórios, a regra da maioria (qualificada, de acordo com certas exigências) é particularmente importante, porque a "racionalidade procedimental" que se atribui a ela (associada ao caráter discursivo dos aconselhamentos precedentes) confere força legitimadora às decisões de maioria. Decisões democráticas de maioria tratam de criar cesuras em um processo argumentativo (temporariamente) interrompido sob o risco de se tomar uma decisão e cujos resultados podem ser aceitos como base para uma práxis obrigatória também pela minoria derrotada nas eleições.

Para o autor, o voto da maioria qualificada exerce legitimação ao processo democrático, na medida em que esse resultado foi formado pelo processo do discurso, pressupondo debates e exposição de múltiplas proposições favoráveis e contrárias. Este processo proporciona aceitação dos resultados, sem necessariamente fazer com que os cidadãos mudem de opinião ou queiram revogar o resultado final. Isto ocorre porque ele foi discutido e acordado pela maioria. Sob esta perspectiva, compreendemos que a principal crítica ocorra mediante a consciência das massas durante o processo e, principalmente, no querer participar.

Entendemos que a democracia deliberativa de Habermas $(1995,2002)$ é uma tentativa de reconciliação entre a teoria clássica e as teorias consideradas modernas. Esta reconciliação possui, como foco principal, o papel da participação das massas. Para além, o autor discorre sobre questões que perpassam as sociedades atuais, consideradas por alguns autores como pós-modernas, como as questões de múltiplas culturas, valores axiológicos diferenciados, o papel das minorias, etc.

\section{As teorias: aproximações}

Vimos que a democracia em Schumpeter (1984), rompeu com as concepções da teoria clássica, propondo uma visão realista; porém, de cunho normativo. A sua teoria se desenvolve sob um forte apelo científico, o qual emergia na época, e indicava a não participação das massas, consideradas sem consciência mínima para opinar de forma inteligente. A participação sob este prisma aconteceria, somente, por meio do voto. 
A democracia em Habermas (1995, 2002), como exposto, segue um movimento contrário, resgata a participação das massas e indica a ênfase no processo, na tomada de consciência pelos cidadãos por meio da teoria do discurso. Esta teoria aponta, na eficácia de aprendizagem durante o processo, mediante debates de opiniões contrárias, argumentações racionais e viáveis, e cursos de aconselhamento. Neste sentido, a instituição possui a responsabilidade, pelo Direito, de fomentar estruturas de participação e implementar espaços para debates e cursos no sentido de aprimoramento da tomada de consciência da população sobre as questões políticas.

A questão que converge nas duas teorias expostas é a mudança no princípio de participação das massas, o que, nas teorias expostas, são completamente opostas. Para Schumpeter (1984) é desnecessária; para Habermas $(1995,2002)$, não é somente necessária, mas um quesito essencial para a legitimidade da democracia.

Entendemos que as duas teorias indicam a democracia como um método governamental, como uma forma de Estado. Os autores trazem argumentações que sustentam suas metodologias. Em Schumpeter, de forma realista; porém, com uma proposta de cunho normativo, descreve o que podemos observar empiricamente. Em Habermas, com um caráter utópico, se prende em meios que possam trazer consciência à população de massas, como já exposto, mediante a teoria do discurso.

Assim, ao pensar as teorias postas no âmbito da gestão democrática escolar, podemos fazer um comparativo de como estão sendo discutidos os princípios democráticos em documentos como o Projeto Político Pedagógico, Regimento interno, Planejamento de aula, etc., bem como as ações realizadas pelos sujeitos. Ou seja, qual conceito de democracia está sendo propagado? 0 escrito está em consonância com o praticado? Quem é chamado a participar? Como é realizada esta participação?

\section{Considerações Finais}

Entendemos que as discussões sobre o tema democracia, nos dois autores, ainda não estão encerradas. A proposta do presente artigo foi levantar reflexões iniciais, com o intuito de fomentar discussões e problematizações futuras, principalmente no âmbito escolar, visto que um de seus princípios é o de desenvolvimento de uma gestão democrática. Ressaltamos que, sendo a sociedade atual complexa, os autores clássicos e com uma vasta produção, também se torna complexa a apropriação desta realidade. 
Portanto, em uma aproximação inicial sobre a teoria de democracia nos dois autores, destacamos que, para ambos, o conceito de democracia está ancorado em um método, e eles criam estratégias para o desenvolvimento governamental. Também trazem argumentações quanto à eficácia e modos de implementação de suas teorias.

A principal diferença consiste no grau de participação popular das massas. Para Schumpeter (1984), é um quesito desnecessário, pois a população não desenvolveu um grau de consciência e inteligência necessárias para participar das questões políticas. Portanto, sua participação se resume ao voto de seus representantes, sendo eles autônomos. Sua opinião é formada por meio de propaganda em uma competição entre os partidos.

Para Habermas $(1995,2002)$, a questão da participação popular é estritamente necessária, é o que legitima a democracia. A consciência da maioria seria adquirida por meio de debates no processo de eleições, por exemplo, para além de processos concomitantes nas deliberações que trouxessem racionalidade aos debates. 0 autor indica a urgência da participação da maioria em uma sociedade complexa, multicultural e globalizada.

Neste sentido, apesar de não acreditarmos na compatibilidade entre democracia e capitalismo, tendemos a aceitar a proposta de Habermas. Para nós, apesar de reformista, ela se propõe a superar as teorias que deixam a decisão apenas para as elites, incluindo a participação popular das massas no processo deliberativo. Parece utópico, mas entendemos que toda realidade, um dia, já foi considerada utópica.

Neste prisma, o âmbito educacional é uma das arenas destas práticas teóricas. Estudá-las nos traz consciência de como está sendo desenvolvida a gestão democrática escolar, quais seus princípios e o que a fundamenta. A compreensão aprofundada das teorias que discorrem sobre a democracia é um dos pilares que podem auxiliar a nossa ação enquanto educadores, no sentido de nos aproximarmos de uma gestão democrática.

\section{Referências}

ARRETCHE, M. Emergência e desenvolvimento do Welfare State: teorias explicativas. Boletim Informativo e Bibliográfico das Ciências Sociais. n. 39. Rio de Janeiro: Anpocs, 1995.

BARROS, A.; BARBOSA, M. L.; ALVES, B. G. Refletindo sobre o welfare state e a criseestrutural do capital. Ciências humanas e sociais, Maceió, v. 2, n.1, p. 87-102, mai. 2014. 
$<\underline{\text { https://periodicos.set.edu.br/index.php/fitshumanas/article/view/1316/789>. }}$ Acesso em: 05 jun. 2017.

BARROSO, J. O Estado, a educação e a regulação das políticas. Educação e Sociedade, Campinas, v. 26, n. 92, p. 725-751, out. 2005.

HABERMAS, J. Três Modelos Normativos de Democracia. Lua Nova. Revista de Cultura e Política, São Paulo, n. 36, p. 39-53, 1995.

J. 0 que significa política deliberativa? In: A inclusão do outro: estudos de teoria política. São Paulo: Edições Loyola, 2002.

LIBÂNEO, J. C.; OLIVEIRA, J. F. e TOSCHI, M. S. Educação Escolar: políticas, estrutura e organização. 10. ed., São Paulo: Cortez, 2012.

NOBRE, M. Participação e deliberação na teoria democrática: uma introdução. In: COELHO, V. S. P.; NOBRE, M. (orgs.). Participação e deliberação. São Paulo: Editora 34, 2004.

PATEMAN, C. Teorias recentes da democracia e o "mito clássico". In: Participação e teoria democrática. Tio de Janeiro: Paz e Terra, 1992.

RÊGO, W. D. L. Notas sobre o conceito de democracia em Joseph A. Schumpeter e Hans Kelsen. In: ENCONTRO ANUAL DA ANPOCS, 18, 1994, Caxambu - MG. Anais. Caxambu MG, 1994. p. 1-31.

SCHUMPETER, J. A. Capitalismo, Socialismo e Democracia. Rio de Janeiro: Zahar Editores, 1984.

UGARTE, P. S. Que participação para qual democracia? In: COELHO, V. S. P.; NOBRE, M. (orgs.). Participação e deliberação. São Paulo: Editora 34, 2004. 


\section{JORNAL DE POLÍTICAS EDUCACIONAIS

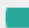

\section{$\Theta$}

O Copyright é retido pelo/a autor/a (ou primeiro co-autor) que outorga o direito da primeira publicação ao Jornal de Políticas Educacionais. Mais informação da licença de CreativeCommons encontram-se em http://creativecommons.org/licenses/by-nc-nd/2.5. Qualquer outro uso deve ser aprovado em conjunto pelo/s autor/es e pelo periódico.

JoRnal DE PolíticAs EdUCACIONAIS é uma publicação do Núcleo de PolíticasEducacionaisdo Setor de Educação da Universidade Federal do Paraná - NuPE/UFPR, em consórcio com a Linha de Pesquisa em Políticas Educacionais do Programa de Pós-Graduação em Educação - PPGE/UFPR, que aceita colaboração, reservando-se o direito de publicar ou não o material espontaneamente enviado à redação. As colaborações devem ser enviadas ao NuPE/UFPR, conforme orientações contidas nas páginas do periódico na internet: http://revistas.ufpr.br/ipe.

Indexação:

BBE - Biblioteca Brasileira de Educação (MEC/INEP)

Clase (Base de Datos Bibliográfica de Revistas de Ciencias Sociales y Humanidades)

Diadorim - Diretório de Política de Acesso Aberto das Revistas Científicas Brasileiras (IBICT) Google Scholar

Index Copernicus

Portal de Periódicos (CAPES)

SER - Sistema Eletrônico de Revistas da Universidade Federal do Paraná (SER/UFPR)

Sumários de Revistas Brasileiras (FUNPEC-RP)

DRJI - Directory of Research Journals Indexing

(Periódico integralmente disponível apenas em via eletrônica)

Jornal de Políticas Educacionais / Núcleo de Políticas Educacionais da Universidade Federal do Paraná NuPE/UFPR - v.1, n. 1 (1ํㅗ semestre de 2007) - Curitiba: NuPE/UFPR.

Volume 12, número 15 - Agosto de 2018

ISSN 1981-1969

1. Educação - Periódicos. 2. Política Educacional - Periódicos. I. NuPE/UFPR

Comitê Editorial:

Elisângela Scaff (UFPR)

Ana Lorena Bruel (UFPR)

Marcos Alexandre Ferraz (UFPR)

Conselho Editorial:

Andréa Barbosa Gouveia (UFPR), Ângela Hidalgo (UNICENTRO), Ângelo Ricardo de Souza (UFPR), Cesar GernominoTello (Universidad Nacional TresFebrero, Argentina),Gladys Beatriz Barreyro (USP), Juca Gil (UFRGS), Jefferson Mainardes (UEPG), João Ferreira de Oliveira (UFG), Luiz Souza Júnior (UFPB), Marcos Edgard Bassi (UFSC), Regina Maria Michelotto (UFPR), Robert Verhine (UFBA), Rosana Cruz (UFPI), Rubens 
SAKATA, K. L.; LIMA, M. F. Apontamentos sobre o conceito de democracia em Joseph A. Schumpeter e Jürgen Habermas.

Barbosa Camargo (USP), Sebastián Donoso Díaz (Universidad de Talca, Chile), Taís Moura Tavares (UFPR), TheresaAdrião (UNICAMP), Vera Peroni (UFRGS).

\author{
Jornal de Políticas Educacionais \\ Universidade Federal do Paraná \\ Setor de Educação \\ Núcleo de Políticas Educacionais - NuPE/UFPR \\ Rua Gal. Carneiro, 460 - 4o andar - Sala 407/C \\ 80.060-150 - Curitiba - PR - Brasil \\ Tel.: 41-3360-5380 \\ jpe@ufpr.br \\ http://revistas.ufpr.br/jpe
}

